\title{
Depression Increases Stroke Hospitalization Cost: An Analysis of 17,010 Stroke Patients in 2008 by Race and Gender
}

\author{
Baqar Husaini, ${ }^{1}$ Robert Levine, ${ }^{2}$ Linda Sharp, ${ }^{3}$ Van Cain, ${ }^{1}$ Meggan Novotny, ${ }^{1}$ Pamela Hull, \\ Gail Orum, ${ }^{5}$ Zahid Samad, ${ }^{1}$ Uchechukwu Sampson, ${ }^{4}$ and Majaz Moonis ${ }^{6}$ \\ ${ }^{1}$ Tennessee State University, Nashville, TN 37209, USA \\ ${ }^{2}$ Meharry Medical College, Nashville, TN 37208, USA \\ ${ }^{3}$ Harbor-UCLA Medical Center, Los Angeles, CA 90095, USA \\ ${ }^{4}$ Vanderbilt University, Nashville, TN 37203, USA \\ ${ }^{5}$ Charles R. Drew University, Los Angeles, CA 90059, USA \\ ${ }^{6}$ University of Massachusetts, Boston, MA 01655, USA
}

Correspondence should be addressed to Baqar Husaini; bhusaini@tnstate.edu

Received 17 December 2012; Accepted 31 January 2013

Academic Editor: V. Padma

Copyright (C) 2013 Baqar Husaini et al. This is an open access article distributed under the Creative Commons Attribution License, which permits unrestricted use, distribution, and reproduction in any medium, provided the original work is properly cited.

Objective. This analysis focuses on the effect of depression on the cost of hospitalization of stroke patients. Methods. Data on 17,010 stroke patients (primary diagnosis) were extracted from 2008 Tennessee Hospital Discharge Data System. Three groups of patients were compared: (1) stroke only $\left(\mathrm{S}^{\mathrm{O}}, n=7,850\right)$, (2) stroke + depression $\left(\mathrm{S}^{+\mathrm{D}}, n=3,965\right)$, and (3) stroke + other mental health diagnoses $\left(\mathrm{S}^{+\mathrm{M}}, n=5,195\right)$. Results. Of all adult patients, $4.3 \%$ were diagnosed with stroke. Stroke was more prevalent among blacks than whites ( $4.5 \%$ versus $4.2 \%, P<0.001)$ and among males than females $(5.1 \%$ versus $3.7 \%, P<0.001)$. Nearly one-quarter of stroke patients (23.3\%) were diagnosed with depression/anxiety. Hospital stroke cost was higher among depressed stroke patients $\left(\mathrm{S}^{+\mathrm{D}}\right)$ compared to stroke only $\left(\mathrm{S}^{\mathrm{O}}\right)$ patients $(\$ 77,864$ versus $\$ 47,790, P<0.001)$, and among $\mathrm{S}^{+\mathrm{D}}$, cost was higher for black males compared to white depressed males ( $\$ 97,196$ versus $\$ 88,115, P<0.001)$. Similar racial trends in cost emerged among $S^{+D}$ females. Conclusion. Depression in stroke patients is associated with increased hospitalization costs. Higher stroke cost among blacks may reflect the impact of comorbidities and the delay in care of serious health conditions. Attention to early detection of depression in stroke patients might reduce inpatient healthcare costs.

\section{Background}

Between $20 \%$ and $60 \%$ of stroke patients are diagnosed with depression/anxiety [1], and these are often newly diagnosed in stroke patients both during hospitalization and up to 3 years after discharge [1-20]. Depression is associated with longer institutionalization and poorer rehabilitation outcomes $[21,22]$. Further, depression is more often diagnosed for females and white stroke patients [23, 24], and it is correlated with higher rates of suicidal ideation and stroke mortality [25-27]. Depression increases the risk of stroke [28] as well as increased healthcare costs [29-34]. As these and other stroke related factors are evaluated, understanding their impact on healthcare cost is necessary for better management, improved therapeutic outcomes, and reduced healthcare cost.

\section{Depression and Healthcare Cost}

Several studies have reported the effect of depression/anxiety on healthcare costs. For example, while female Medicare patients had a higher prevalence of depression and higher use of outpatient services, inpatient hospital costs for male patients were $47 \%$ higher compared to females ( $\$ 15,060$ versus $\$ 10,240, P<0.001$ ) [30]. In another study, the medical cost of depressed patients was $54 \%$ higher compared to nondepressed patients [34]. While higher cost among stroke 
patients is associated with greater number of readmissions, longer hospitalizations, and greater number of outpatient visits compared to a control group without depression, evidence is sparse about whether these costs vary by race and gender.

In this study of Tennessee stroke patients $(n=17,010)$, we examine two issues: (1) prevalence of depression among stroke patients by race and gender and (2) the effect of depression on total hospitalization cost in 2008 by race and gender.

\section{Methods}

3.1. Data. We obtained inpatient discharge data from the 2008 Tennessee Hospital Discharge Data System (HDDS) compiled by The Tennessee Department of Health's (TDH) Division of Health Statistics. All hospitals licensed by the $\mathrm{TDH}$ are required by law to report patient-level discharge information. Data are reported on a uniform billing form developed by the National Uniform Billing Committee. Diagnoses in the administrative files are given by the attending physicians (according to the ICD-9 codes), and it is unclear what tests are used in arriving at those diagnoses. Further, these diagnoses appear only when the patient is treated for those conditions in the hospital. We extracted data on primary diagnosis of stroke (ICD-9 codes of 430-438) along with the secondary diagnoses of depression/anxiety (ICD-9 codes 296.2-major depressive disorder, single episode, 292.3 - major depressive disorder, recurrent episode, 3000.4-neurotic depression, 309.0-brief depressive reaction, 309.1-prolonged depressive reaction, 311-depressive disorder, not elsewhere classified, and 300-anxiety states, hysteria, phobic disorders, and neurotic depression) for blacks and whites since they constitute $97 \%$ of Tennessee population. Since there is a high overlap in symptoms of depression and anxiety ranging from $48 \%$ to $74 \%[37,38]$, we combined the diagnoses for depression and anxiety as a single variable for our analysis. Data extraction on stroke patients included sex, age, race, days of hospitalization, number of re-admissions, and costs associated with stroke treatment as well as the total hospital charges for the entire year of 2008 when the patient was readmitted for illnesses other than stroke. Extracted data also included co-morbidities such as atrial fibrillation, hypertension, diabetes, cholesterol, and cardiovascular events such as heart attacks. The stroke sample included whites (82\%) and females (55\%), and the average age in the sample was 70 years. Stroke rates were age adjusted per 2000 US population.

3.2. Statistical Analysis. Analysis of variance compared the average hospitalization costs [39] for three groups of stroke patients: (1) stroke only $\left(\mathrm{S}^{\mathrm{O}}, n=7,850\right)$, (2) stroke + depression/anxiety $\left(\mathrm{S}^{+\mathrm{D}}, n=3,965\right)$, and (3) stroke + other mental diagnoses $\left(S^{+M}, n=5,195\right)$. The Fisher exact test was used for comparison of healthcare cost and prevalence of comorbidities by race and sex. Percentages of stroke diagnoses were compared using Pearson's Chi-squared test with Yates' correction for continuity, and odd ratios (ORs) were obtained through logistic regression analyses, which controlled for age, sex, hypertension, diabetes, cholesterol, and atrial fibrillation. A probability value of $P<0.05$ was the accepted threshold for statistical significance.

\section{Results}

4.1. Prevalence of Stroke, Depression, Comorbidities, and Healthcare Cost. Our analysis showed that 17,010 patients (4.3\% of all 400, 235 adult patients) had a primary diagnosis of stroke with an age-adjusted prevalence rate of 370.6 per $100 \mathrm{~K}$. Stroke was higher among blacks compared to whites $(4.5 \%$ versus $4.2 \%$, resp., $P<0.0001$; prevalence rates of 517.1 versus 322.0, resp.; $\mathrm{OR}=1.31,95 \% \mathrm{CI}=1.26-1.36$ after controlling for risk factors, Table 1). Stroke was more prevalent among males than females $(5.1 \%$ versus $3.7 \%, P<0.0001$; rates of 374.1 versus 369.2 per $100 \mathrm{~K}$; OR $=1.22$, 95\% CI $=1.18-$ 1.25). Further, stroke was more common among black males compared to white males $(5.8 \%$ versus $5.0 \%, P<0.001$; prevalence rates of 532.3 versus 351.0 per $100 \mathrm{~K}$; OR $=1.31$, $95 \% \mathrm{CI}=1.23-1.39)$ and among black females compared to white females (3.9\% versus $3.7 \%, P<0.02$; prevalence rates of 505.7 versus 298.9 per $100 \mathrm{~K}$; $\mathrm{OR}=1.29,95 \% \mathrm{CI}=1.22-1.37$ ). Nearly one-quarter of stroke patients were depressed/anxious (23.3\%). Depression among stroke patients was higher among whites than blacks (25.1\% versus $15.2 \%, P<0.001)$ and among females than males $(27.5 \%$ versus $18.3 \%, P<0.001)$.

Table 1 shows that nearly $20 \%(3,402$ of 17,010$)$ of stroke patients had congestive heart failure (CHF) and $4 \%$ had experienced heart attacks (MI). Coronary heart disease (CHD) was also more prevalent among the stroke patients $(39 \%$ overall, $41 \%$ among whites versus $30 \%$ among blacks). Other stroke co-morbidities varied by race and sex. Hypertension (92\%) and diabetes (45\%) were more prevalent among blacks and atrial fibrillation (32\%) and high cholesterol (17\%) were more prevalent among white patients.

Table 1 further shows that treatment cost associated with stroke only $\left(\mathrm{S}^{\circ}\right)$ was higher among blacks as compared to whites ( $\$ 41,370$ versus $\$ 30,215, P<0.001$, a difference of $36.9 \%)$. This cost difference also exists when the average annual costs for the entire year of 2008 is examined for patients without stroke. Here again, nonstroke black patients compared to nonstroke white patients had higher 2008 cost (\$45,892 versus $\$ 40,376, P<0.001)$, partly due to longer hospitalization for black patients (8.6 days for blacks versus 7.3 days for whites, $P<0.001)$. The cost differential remained intact when the comparisons are made simply for stroke cost (\$74,338 for blacks versus $\$ 55,884$ for whites, $P<0.001$ ) or the cost for the entire year of 2008 with multiple readmissions $(\$ 74,338$ for blacks versus $\$ 55,884$ for whites, $P<0.001)$. Similar trends for stroke cost emerged for black males $(\$ 74,006$ versus $\$ 59,403, P<0.001)$ and for black females $(\$ 74,589$ versus $\$ 52,877, P<0.001)$. Again, higher costs among blacks reflected higher comorbidities and longer hospitalizations for blacks than whites. Thus, black stroke patients (due to high comorbidities and longer hospitalization) cost $62 \%$ more than nonstroke black peers $(\$ 74,338$ versus $\$ 45,892$, a difference of $\$ 28,446)$ and more 
TABLE 1: Age-adjusted stroke rates and characteristics by race and gender in $2008(n=17,010)$.

\begin{tabular}{|c|c|c|c|c|c|c|c|c|c|}
\hline Variables & $\begin{array}{c}\text { WF } \\
n=7495\end{array}$ & $\begin{array}{c}\text { WM } \\
n=6405\end{array}$ & $\begin{array}{c}\text { BF } \\
n=1773\end{array}$ & $\begin{array}{c}\text { BM } \\
n=1337\end{array}$ & $\begin{array}{c}\text { Total } \\
n=17,010\end{array}$ & $\begin{array}{c}\text { Any stroke } \\
\text { blacks } \\
n=3110\end{array}$ & $\begin{array}{c}\text { Blacks } \\
\text { no stroke } \\
n=65,595\end{array}$ & $\begin{array}{c}\text { Any stroke } \\
\text { whites } \\
n=13,900\end{array}$ & $\begin{array}{c}\text { Whites } \\
\text { no stroke } \\
n=317,630\end{array}$ \\
\hline Stroke rate per $100 \mathrm{~K}$ & 298.9 & 351.0 & 505.7 & 532.3 & 370.6 & 517.1 & - & 322.0 & - \\
\hline Age & 73 & 69 & 64 & 61 & 70 & 63 & 49 & 77 & 57 \\
\hline MI\% & 3.8 & 4.2 & 3.6 & $5.3^{+}$ & 4.1 & 4.3 & 3.1 & 4.0 & $4.4^{*}$ \\
\hline $\mathrm{CHF} \%$ & 19.5 & 17.9 & 20.1 & $21.3^{*}$ & 19.1 & $20.6^{*}$ & $14.5^{*}$ & 18.7 & 13.6 \\
\hline $\mathrm{CHD} \%$ & $31.7^{*}$ & 31.4 & 23.6 & 24.3 & 38.9 & 29.8 & 17.5 & 41.0 & $25.8^{*}$ \\
\hline At fib\% & $32^{*}$ & 31 & 24 & 24 & 30 & 24 & 13.0 & $32^{*}$ & $18.6^{*}$ \\
\hline Нyр\% & 85 & 84 & 92 & $92^{*}$ & 86 & $92^{*}$ & 54 & 84.5 & 52 \\
\hline Diabetes\% & 31 & 36 & $47^{*}$ & 42 & 36 & $45^{*}$ & 27.4 & 34 & 22.7 \\
\hline Chol\% & 15.8 & $17.3^{*}$ & 11.3 & 13.4 & 15.7 & 12.2 & 5.1 & $16.5^{*}$ & $8.2^{*}$ \\
\hline Dep/anx\% & $29.7^{*}$ & 19.8 & 18.3 & 11.0 & 23.3 & 15.2 & 10.7 & $25.1^{*}$ & $21.4^{*}$ \\
\hline $\begin{array}{l}\text { Number of } \\
\text { readmissions }\end{array}$ & 1.11 & 1.12 & 1.13 & 1.13 & 1.12 & 1.13 & 1.6 & 1.11 & 1.5 \\
\hline Hop stk day & 5.0 & 5.1 & 7.1 & 7.3 & 5.4 & $7.2^{*}$ & - & 5.0 & - \\
\hline Tot hos day & 11.3 & 11.7 & 15.7 & 15.4 & 12.2 & $15.6^{*}$ & $8.6^{*}$ & 11.5 & 7.3 \\
\hline Average ischemic \$ & 27,071 & 30,904 & $43,074^{*}$ & 38,710 & 31,460 & $41,120^{*}$ & - & 28,833 & - \\
\hline Average hemo. \$ & 45,852 & 50,017 & $69,796^{*}$ & 60,586 & 51,211 & $64,643^{*}$ & - & 48,246 & - \\
\hline $\begin{array}{l}\text { Average } \\
\text { Total stroke } \$^{+}\end{array}$ & 29,238 & 31,359 & 41,207 & $41,586^{*}$ & 32,255 & $41,370^{*}$ & - & 30,215 & - \\
\hline All 2008 admis \$ & 52,877 & 59,403 & 74,589 & 74,006 & 59,259 & 74,338 & $45,892^{*}$ & 55,884 & 40,376 \\
\hline
\end{tabular}

${ }^{+}$Average cost for all strokes combined includes cost associated with ischemic + hemorrhagic + unspecified strokes + TIA; \# is average number of admissions/hospital days; CHF: congestive heart failure; CHD: coronary heart disease; all costs are reported in averages. Average of all total 2008 cost includes cost combined for all admissions in 2008.

* Fisher's exact test differences are significant between nonstroke black and white patients at $P<0.001$.

than $80 \%$ of the cost for white nonstroke patients $(\$ 74,338$ versus $\$ 40,376)$. Comparable race and gender differences also existed in costs associated with ischemic or hemorrhagic stroke (see Table 1). In summary, black patients had higher costs associated with hospitalizations compared to white patients no matter how the costs were examined.

4.2. Effect of Depression on Hospital Cost for Stroke. We examined cost and associated co-morbidities including Charlson Index of comorbidity for three stroke groups including: (1) patients with stroke only $\left(\mathrm{S}^{\mathrm{O}}\right)$; (2) patients with stroke + depression $\left(\mathrm{S}^{+\mathrm{D}}\right)$; (3) stroke patients with other mental diagnoses $\left(S^{+M}\right)$. Within each stroke category, we compared cost and associated factors by race and gender. Table 2 shows that the average healthcare cost was nearly $63 \%$ higher for stroke patients with $S^{+D}$ compared to $S^{\mathrm{O}}$ (\$77,864 versus $\$ 47,790, P<0.001$, a difference of $63 \%)$ or $S^{+D}$ compared to $S^{+M}$ ( $\$ 77,864$ versus $\$ 62,387, P<0.001$, a difference of $24.8 \%)$. Clearly, these data show that depression among stroke patients is associated with higher hospital costs compared with stroke patients who have other mental illnesses.

Table 2 provides costs and comorbidities data for three groups of stroke patients, further illustrating that both stroke prevalence and annual costs were higher among blacks, and the race-sex differences are made evident. Among depressed stroke patients $\left(\mathrm{S}^{+\mathrm{D}}\right)$, black males had higher annual hospital charges compared to white males ( $\$ 97,196$ versus $\$ 88,115$, $P<0.001)$, in part due to longer hospital stays compared to white males (24.6 versus $20.2, P<0.001$ ). Similarly, black $\mathrm{S}^{+\mathrm{D}}$ females had higher cost compared to white $\mathrm{S}^{+\mathrm{D}}$ females $(\$ 95,269$ versus $\$ 68,184, P<0.001)$. For black males, the higher cost cannot be attributed to depression/anxiety as only $11 \%$ of black males had a diagnosis of depression; the higher cost here appears to reflect complexities (denoted by a higher Charlson comorbidity index) that develop from co-morbid conditions such as higher prevalence of hypertension and diabetes. Similar race and gender trends also existed for black males and females across $\mathrm{S}^{+\mathrm{M}}$ and $\mathrm{S}^{\mathrm{O}}$ groups of patients.

\section{Comments}

Previous studies on healthcare cost have reported substantially higher cost (54\% higher) for patients with cardiovascular disease (CVD) and stroke in association with depression and anxiety [31-34]. Our analyses show that depression and anxiety among Tennessee stroke patients is associated with a $63 \%$ increase in the annual hospital care cost. Further, our findings of higher cost for depressed stroke patients, especially among women, are consistent with those reported previously [34]. Since depression can be considered as an independent risk factor for CVD [40,41] and since women outnumber men in the population (as well as in our $\mathrm{S}^{+\mathrm{D}}$ group-54\% versus $46 \%$ ), costs attributable to depression 
TABLE 2: Three stroke group cost by race and gender, 2008.

\begin{tabular}{|c|c|c|c|c|c|c|c|c|c|c|c|c|}
\hline & \multicolumn{4}{|c|}{$\begin{array}{c}\text { Stroke only } S^{\circ}, n=7,850 \\
\text { age }=71 ; \\
\text { entire } 2008 \text { cost }=\$ 47,790\end{array}$} & \multicolumn{4}{|c|}{$\begin{array}{c}\text { Stroke + Dep S } S^{+D}, n=3,965 \\
\text { age }=68 \\
\text { entire } 2008 \text { cost }=\$ 77,864^{*}\end{array}$} & \multicolumn{4}{|c|}{$\begin{array}{c}\text { Stroke }+ \text { other ment } \mathrm{S}^{+\mathrm{M}} \\
n=5,195 ; \\
\text { age }=69 ; \\
\text { entire } 2008 \text { cost }=\$ 62,387\end{array}$} \\
\hline & WF & WM & $\mathrm{BF}$ & $\mathrm{BM}$ & WF & WM & $\mathrm{BF}$ & $\mathrm{BM}$ & WF & WM & $\mathrm{BF}$ & $\mathrm{BM}$ \\
\hline Mean age & 75 & 71 & 64 & 61 & 71 & 67 & 62 & 61 & 73 & 67 & 65 & 61 \\
\hline HTN\% & 84 & 83 & 91 & 91 & 87 & 89 & 96 & 93 & 83 & 83 & 91 & 92 \\
\hline Diabetes $\%$ & 31 & 36 & 48 & 47 & 34 & 42 & 55 & 48 & 30 & 32 & 42 & 36 \\
\hline $\mathrm{CHF} \%$ & 17 & 15 & 17 & 21 & 23 & 25 & 26 & 29 & 20 & 19 & 22 & 20 \\
\hline MI\% & 2.9 & 3.3 & 3.4 & 3.5 & 4.4 & 6.5 & 3.4 & 7.5 & 5.0 & 4.2 & 4.1 & 6.4 \\
\hline Atrial fibrillation & $31^{*}$ & 30 & 22 & 23 & 32 & 36 & 24 & 31 & $32^{*}$ & 30 & 26 & 24 \\
\hline Hospital days & 8.1 & 7.8 & 12.7 & 12.8 & 15.7 & 20.2 & 21.9 & 24.6 & 11.6 & 12.2 & 16.9 & 15.6 \\
\hline Number of Admissions & 1.7 & 1.7 & 1.9 & 1.8 & 3.0 & 3.6 & 2.9 & 3.2 & 2.2 & 2.1 & 2.3 & 2.3 \\
\hline Comorb Index ${ }^{++}$ & 1.4 & 1.5 & 1.7 & $1.9^{*}$ & 1.6 & 1.9 & 2.1 & $2.3^{*}$ & 1.7 & 1.8 & $1.9^{*}$ & 1.7 \\
\hline Total stroke cost combined \$ & 27,601 & 28,926 & 39,500 & $40,866^{*}$ & 31,369 & 32,488 & $39,482^{*}$ & 37,773 & 29,630 & 34,209 & $44,914^{*}$ & 43,140 \\
\hline $\begin{array}{l}\text { Annual cost for all } \\
2008 \text { admissions } \$\end{array}$ & 42,329 & 46,210 & 63,072 & $64,622^{*}$ & 68,184 & 88,115 & 95,269 & $97,196^{*}$ & 53,575 & 61,155 & $80,849^{*}$ & 77,076 \\
\hline
\end{tabular}

${ }^{*}$ Differences significant at $P<0.001 ;{ }^{++}$Charlson Comorbidity Index-higher score denote greater number of comorbid conditions.

may be reduced by early diagnosis and treatment of depression. The stroke patients in our sample had higher prevalence of both hypertension (more than $80 \%$ ) and diabetes (more than $35 \%$ ). Addressing depression and reducing risk factors through preventive programs [42] could substantially reduce the morbidity, mortality, and healthcare costs associated with stroke $[42,43]$.

The average healthcare cost among blacks compared to whites were higher regardless of whether the stroke was hemorrhagic or ischemic (hemorrhagic cost $-\$ 64,643$ versus $\$ 48,246 P<0.001$; ischemic cost $-\$ 41,120$ versus $\$ 28,833$, $P<0.001)$. These higher costs remained intact when total stroke costs (combined ischemic+hemorrhagic+unspecified stroke + TIA) were compared between blacks and whites ( $\$ 41,370$ versus $\$ 30,215, P<0.001)$, particularly black males compared to white males ( $\$ 41,586$ versus $\$ 31,359, P<0.001$ ). The same cost pattern emerges when the annual cost for the entire 2008 year was combined (blacks had higher annual cost compared to whites: $\$ 74,338$ versus $\$ 55,884, P<0.001$, Table 1) and when racial comparisons for nonstroke patients were made. These differences suggest that blacks with chronic conditions may seek medical services later in the progression of their disease and that this late entry to care $[44,45]$ may require more services and longer hospitalization as is evident in our data (16 days for black patients compared to 12 days for white patients, Table 1). Further, the higher cost among black males may in part exist because previous studies suggest that they are more likely to drop out of behavioral and pharmacological therapies [46] which in turn leads to more complications and readmissions (re-admissions are higher among blacks - see Table 1).

The lower overall cost of care among women (particularly white women) compared to men may result from a number of factors including that women, in general, seek professional help earlier on in the development of their illness compared to men $[47,48]$ and this alone may reduce complications and hence reduce length of hospitalization and cost [4749]. In order to impact CVD end points among women, depression/anxiety must be treated both as independent risk factors for preventing CVD and for reducing cost in females with known CVD [50].

Finally, Our findings of higher hospitalization cost of stroke is associated with depression and anxiety that consistently appear as a co-morbid condition requiring greater attention in managing healthcare cost. Findings of higher cost and greater utilization of services, though scantly reported (see Table 3 below), nonetheless are supportive of monitoring ways to contain higher treatment cost associated with stroke and other major events.

\section{Limitations}

The administrative hospital discharge files do not provide clinical data regarding severity/duration of diseases, test results, or cost of pharmacological treatment provided. Further, these administrative files do not provide itemized cost, and hence it is impossible to determine the cost of pharmacological treatment for depression/anxiety for any patient. The administrative data only include the total cost for the entire hospital stay, number of admissions, and sometimes within the total cost per admission, the cost associated with major procedures such as CABG. In addition to the primary diagnosis, these administrative files provide data on secondary diagnoses (i.e., co-morbidities) only when treatment is provided for those conditions. These administrative files lack clinical details of diagnoses or co-morbid conditions which may shed additional light on racial and gender differences in healthcare cost. Our data are from a single state and for only one year (2008), and as such they may not reflect outcomes from other geographic areas/regions. Finally, based on this 
TABLE 3: Increased medical care costs of stroke associated with depression. Recent peer-reviewed publications.

\begin{tabular}{|c|c|c|c|c|c|}
\hline $\begin{array}{l}\text { First author } \\
\text { and year }\end{array}$ & Country & Type of study & Participants & Results & Conclusions \\
\hline $\begin{array}{l}\text { Bhattarai et al., } \\
\text { [35] } 2012\end{array}$ & UK & $\begin{array}{l}\text { Population- } \\
\text { based } \\
\text { cohort }\end{array}$ & $\begin{array}{l}299,912 \\
\text { participants, } \\
\text { ages } 30 \text { to } 100 \\
\text { years }\end{array}$ & $\begin{array}{l}14 \% \text { of male and } 26 \% \text { of female stroke } \\
\text { patients with single morbidity had } \\
\text { comorbid depression; patients with } \\
\text { concurrent diabetes, CHD, and stroke } \\
\text { had a very high prevalence of } \\
\text { depression (men } 23 \% \text { and women } \\
49 \% \text { ) }\end{array}$ & $\begin{array}{l}\text { Compared to those with no } \\
\text { morbidity, depression was } \\
\text { associated with higher rates of } \\
\text { healthcare utilization and increased } \\
\text { costs at any level of morbidity. }\end{array}$ \\
\hline $\begin{array}{l}\text { Sicras et al., } \\
\text { [36] } 2008\end{array}$ & Spain & $\begin{array}{l}\text { Cross- } \\
\text { sectional, } \\
\text { retrospective }\end{array}$ & $\begin{array}{l}2,266 \text { stroke } \\
\text { patients }\end{array}$ & $\begin{array}{l}\text { Females (OR } 2.1 \text { ), obesity (OR } 1.1 \text { ), and } \\
\text { neuropathy (OR } 2.2 \text { ) were significantly } \\
\text { associated with depressive disorder in } \\
\text { stroke patients }\end{array}$ & $\begin{array}{l}\text { Adjusted total costs of depressive } \\
\text { disorder were higher in most } \\
\text { components, euro } 2,-37.55 \text { versus } \\
\text { euro } 1,498.24(P<0.001) \text {. } \\
\text { Medication drugs accounted for } \\
73.4 \% \text { of the total costs. }\end{array}$ \\
\hline $\begin{array}{l}\text { Jia et al., [29] } \\
2006\end{array}$ & USA & $\begin{array}{l}\text { National } \\
\text { cohort }\end{array}$ & $\begin{array}{l}5,825 \\
\text { Department } \\
\text { of Veterans } \\
\text { Affairs } \\
\text { patients with } \\
\text { stroke }\end{array}$ & $\begin{array}{l}41 \% \text { of the sample had poststroke } \\
\text { depression }\end{array}$ & $\begin{array}{l}\text { After adjusting for patient } \\
\text { demographic and clinical factors, } \\
\text { patients with stroke and poststroke } \\
\text { depression had significantly } \\
P<0.0001 \text {, more hospitalization, } \\
\text { outpatient visits, and longer length } \\
\text { of stays, } 12 \text { months after stroke } \\
\text { compared with patients with stroke } \\
\text { but no poststroke depression }\end{array}$ \\
\hline
\end{tabular}

cross-sectional data, we were unable to differentiate prestroke depression from poststroke depression. However, in either case, the association of stroke with depression in our study seems to contribute to increased hospital stay, greater comorbidities, and significantly greater cost of healthcare.

\section{Conclusion}

Stroke patients with depression/anxiety have significantly higher healthcare costs compared to those with stroke only (i.e., without depression/anxiety) or those with other mental health diagnoses. Based on the patterns reported here, greater attention to prevent comorbidities and early detection of depression in stroke patients are all promising interventions aimed at reducing inpatient healthcare costs while improving overall care, with the greatest opportunities for improved health and cost savings in the black male population. Analytic epidemiologic studies are needed to examine whether the higher healthcare costs among blacks exist due to delays in seeking treatment and/or poor access to services, leading to more complex problems and longer hospitalizations. Additionally, research is needed to determine whether aggressive treatment of depressed patients that have suffered stroke might reduce the overall costs of stroke care.

\section{Acknowledgments}

This presentation at the International Society of Hypertension in Blacks (ISHIB) meeting, Boston, July 8-10, 2011, was supported by a Grant from CDC Grant no. U58CCU422782 to Tennessee Department of Health (subcontract no. ED07-20811-00 to Tennessee State University, B. Husaini, PI). Partial support for Drs. R. Levine, B. Husaini, and V. Cain is also provided by a NIH Grant no. P20-MD000516 (National Center on Minority Health and Health Disparity to Meharry Medical College). Dr. U. Sampson was supported in part by the Harold Amos Medical Faculty Development Award of the Robert Wood Johnson Foundation.

\section{References}

[1] G. L. Lenzi, M. Altieri, and I. Maestrini, "Post-stroke depression," Revue Neurologique, vol. 164, no. 10, pp. 837-840, 2008.

[2] U. Sagen, A. Finset, T. Moum et al., "Early detection of patients at risk for anxiety, depression and apathy after stroke," General Hospital Psychiatry, vol. 32, no. 1, pp. 80-85, 2010.

[3] S. L. Barker-Collo, "Depression and anxiety 3 months post stroke: prevalence and correlates," Archives of Clinical Neuropsychology, vol. 22, no. 4, pp. 519-531, 2007.

[4] L. de Wit, K. Putman, I. Baert et al., "Anxiety and depression in the first six months after stroke. A longitudinal multicentre study," Disability and Rehabilitation, vol. 30, no. 24, pp. 18581866, 2008.

[5] H. Sienkiewicz-Jarosz, D. Milewska, A. Bochyńska et al., "Predictors of depressive symptoms in patients with stroke-a threemonth follow-up," Neurologia i Neurochirurgia Polska, vol. 44, no. 1, pp. 13-20, 2010.

[6] V. Morrison, B. Pollard, M. Johnston, and R. MacWalter, "Anxiety and depression 3 years following stroke: demographic, clinical, and psychological predictors," Journal of Psychosomatic Research, vol. 59, no. 4, pp. 209-213, 2005.

[7] M. Åström, "Generalized anxiety disorder in stroke patients a 3year longitudinal study," Stroke, vol. 27, no. 2, pp. 270-275, 1996. 
[8] V. Schepers, M. Post, A. Visser-Meily, I. van de Port, M. Akhmouch, and E. Lindeman, "Prediction of depressive symptoms up to three years post-stroke," Journal of Rehabilitation Medicine, vol. 41, no. 11, pp. 930-935, 2009.

[9] H. Bergersen, K. F. Frøslie, K. Stibrant Sunnerhagen, and A. K. Schanke, "Anxiety, depression, and psychological well-being 2 to 5 years poststroke," Journal of Stroke and Cerebrovascular Diseases, vol. 19, no. 5, pp. 364-369, 2010.

[10] B. Fure, T. B. Wyller, K. Engedal, and B. Thommessen, "Emotional symptoms in acute ischemic stroke," International Journal of Geriatric Psychiatry, vol. 21, no. 4, pp. 382-387, 2006.

[11] J. Z. Willey, N. Disla, Y. P. Moon et al., "Early depressed mood after stroke predicts long-term disability: the Northern Manhattan Stroke Study (NOMASS)," Stroke, vol. 41, no. 9, pp. 1896-1900, 2010.

[12] N. Hadidi, R. Lindquist, D. Treat-Jacobson, and K. Savik, "Natural patterns of change in poststroke depressive symptoms and function," Western Journal of Nursing Research, vol. 33, no. 4, pp. 522-539, 2011.

[13] S. E. Kouwenhoven, M. Kirkevold, K. Engedal, and H. S. Kim, "Depression in acute stroke: prevalence, dominant symptoms and associated factors. A systematic literature review," Disability and Rehabilitation, vol. 33, no. 7, pp. 539-556, 2011.

[14] A. Bour, S. Rasquin, I. Aben, A. Boreas, M. Limburg, and F. Verhey, "A one-year follow-up study into the course of depression after stroke," Journal of Nutrition, Health and Aging, vol. 14, no. 6, pp. 488-493, 2010.

[15] M. C. Christensen, S. A. Mayer, J. M. Ferran, and B. Kissela, "Depressed mood after intracerebral hemorrhage: the fast trial," Cerebrovascular Diseases, vol. 27, no. 4, pp. 353-360, 2009.

[16] A. Verdelho, H. Hénon, F. Lebert, F. Pasquier, and D. Leys, "Depressive symptoms after stroke and relationship with dementia: a three-year follow-up study," Neurology, vol. 62, no. 6, pp. 905-911, 2004.

[17] L. Snaphaan, S. van der Werf, K. Kanselaar, and F. E. de Leeuw, "Post-stroke depressive symptoms are associated with poststroke characteristics," Cerebrovascular Diseases, vol. 28, no. 6, pp. 551-557, 2009.

[18] P. W. Burvill, G. A. Johnson, K. D. Jamrozik, C. S. Anderson, E. G. Stewart-Wynne, and T. M. H. Chakera, "Prevalence of depression after stroke: the Perth Community Stroke Study," British Journal of Psychiatry, vol. 166, no. 3, pp. 320-327, 1995.

[19] I. Zavoreo, V. Bašić-Kes, M. Bosnar-Puretić, and V. Demarin, "Post-stroke depression," Acta Clinica Croatica, vol. 48, no. 3, pp. 329-333, 2009.

[20] I. van de Port, G. Kwakkel, M. Bruin, and E. Lindeman, "Determinants of depression in chronic stroke: a prospective cohort study," Disability and Rehabilitation, vol. 29, no. 5, pp. 353-358, 2007.

[21] P. Masskulpan, K. Riewthong, P. Dajpratham, and V. Kuptniratsaikul, "Anxiety and depressive symptoms after stroke in 9 rehabilitation centers," Journal of the Medical Association of Thailand, vol. 91, no. 10, pp. 1595-1602, 2008.

[22] L. Farner, J. Wagle, K. Engedal, K. M. Flekkøy, T. B. Wyller, and B. Fure, "Depressive symptoms in stroke patients: a 13 month follow-up study of patients referred to a rehabilitation unit," Journal of Affective Disorders, vol. 127, no. 1-3, pp. 211-218, 2010.

[23] B. Poynter, M. Shuman, N. Diaz-Granados, M. Kapral, S. L. Grace, and D. E. Stewart, "Sex differences in the prevalence of post-stroke depression: a systematic review," Psychosomatics, vol. 50, no. 6, pp. 563-569, 2009.
[24] H. Jia, N. R. Chumbler, X. Wang et al., "Racial and ethnic disparities in post-stroke depression detection," International Journal of Geriatric Psychiatry, vol. 25, no. 3, pp. 298-304, 2010.

[25] Y. Kishi, J. T. Kosier, and R. G. Robinson, "Suicidal plans in patients with acute stroke," Journal of Nervous and Mental Disease, vol. 184, no. 5, pp. 274-280, 1996.

[26] C. Ellis, Y. Zhao, and L. E. Egede, "Depression and increased risk of death in adults with stroke," Journal of Psychosomatic Research, vol. 68, no. 6, pp. 545-551, 2010.

[27] L. S. Williams, S. S. Ghose, and R. W. Swindle, "Depression and other mental health diagnoses increase mortality risk after ischemic stroke," American Journal of Psychiatry, vol. 161, no. 6, pp. 1090-1095, 2004.

[28] J. Dong, Y. Zhang, J. Tong, and L. Qin, "Depression and risk of stroke: a meta-analysis of prospective studies," Stroke, vol. 43, pp. 32-37, 2012.

[29] H. Jia, T. M. Damush, H. Qin et al., "The impact of poststroke depression on healthcare use by veterans with acute stroke," Stroke, vol. 37, no. 11, pp. 2796-2801, 2006.

[30] M. J. Burns, V. A. Cain, and B. A. Husaini, "Depression, service utilization, and treatment costs among Medicare elderly: gender differences," Home Health Care Services Quarterly, vol. 19, no. 3, pp. 35-44, 2001.

[31] N. M. Engel-Nitz, S. D. Sander, C. Harley, G. G. Rey, and H. Shah, "Costs and outcomes of noncardioembolic ischemic stroke in a managed care population," Vascular Health and Risk Management, vol. 6, pp. 905-913, 2010.

[32] M. D. Marciniak, M. J. Lage, E. Dunayevich et al., "The cost of treating anxiety: the medical and demographic correlates that impact total medical costs," Depression and Anxiety, vol. 21, no. 4, pp. 178-184, 2005.

[33] J. Unützer, D. L. Patrick, G. Simon et al., "Depressive symptoms and the cost of health services in HMO patients aged 65 years and older: a 4-year prospective study," Journal of the American Medical Association, vol. 277, no. 20, pp. 1618-1623, 1997.

[34] G. A. Nichols, T. J. Bell, K. L. Pedula, and M. O’KeeffeRosetti, "Medical care costs among patients with established cardiovascular disease," The American Journal of Managed Care, vol. 16, no. 3, pp. e86-e93, 2010.

[35] N. Bhattarai, J. Charlton, C. Rudisill, and M. C. Gulliford, "Prevalence of depression and utilization of health care in single and multiple morbidity: a population-based cohort study," Psychological Medicine, 2013.

[36] A. Sicras Mainar, R. Navarro Artieda, M. Blanca Tamayo, J. Rejas Gutiérrez, and J. Fernández de Bobadilla, "Morbidity and costs associated with depressive syndrome in stroke sufferers in a population," Farmacia Hospitalaria, vol. 32, no. 6, pp. 309-314, 2008.

[37] M. Zimmerman, W. McDermut, and J. I. Mattia, "Frequency of anxiety disorders in psychiatric outpatients with major depressive disorder," American Journal of Psychiatry, vol. 157, no. 8, pp. 1337-1340, 2000.

[38] J. A. Lieberman, "Anxiety with comorbid depression: the rule rather than the exception," Psychiatric Times Reporter, pp. 1-6, 2009.

[39] Statistical Package for the Social Sciences (SPSS), 11.0.1, Version 11, McGraw-Hill, New York, NY, USA, 2002.

[40] T. Rutledge, S. E. Linke, B. D. Johnson et al., "Relationships between cardiovascular disease risk factors and depressive symptoms as predictors of cardiovascular disease events in women," Journal of Women's Health, vol. 21, no. 2, pp. 133-139, 2012. 
[41] J. M. Brown, J. C. Stewart, T. E. Stump, and C. M. Callahan, "Risk of coronary heart disease events over 15 years among older adults with depressive symptoms," American Journal of Geriatric Psychiatry, vol. 19, no. 8, pp. 721-729, 2011.

[42] S. Cruz-Flores, A. Rabinstein, J. Biller et al., "Racial-ethnic disparities in stroke care: the American experience: a statement for healthcare professionals from the American Heart Association/American Stroke Association," Stroke, vol. 42, pp. 20912116, 2011.

[43] B. B. Gump, K. A. Matthews, L. E. Eberly, and Y. F. Chang, "Depressive symptoms and mortality in men: results from the multiple risk factor intervention trial," Stroke, vol. 36, no. 1, pp. 98-102, 2005.

[44] A. W. Hsia, A. Castle, J. J. Wing et al., "Understanding reasons for delay in seeking acute stroke care in an underserved urban population," Stroke, vol. 42, no. 6, pp. 1697-1701, 2011.

[45] M. Kamalesh, J. Shen, and W. M. Tierney, "Stroke mortality and race: does access to care influence outcomes?" American Journal of the Medical Sciences, vol. 333, no. 6, pp. 327-332, 2007.

[46] I. M. Lesser, S. Zisook, B. N. Gaynes, S. R. Wisniewski, J. F. Luther, and M. Fava, "Effects of race and ethnicity on depression treatment outcomes: the CO-MED trial," Psychiatric Services , vol. 62, pp. 1167-1179, 2011.

[47] K. D. Bertakis, R. Azari, L. J. Helms, E. J. Callahan, and J. A. Robbins, "Gender differences in the utilization of health care services," Journal of Family Practice, vol. 49, no. 2, pp. 147-152, 2000.

[48] K. M. Brett and C. W. Burt, "Utilization of ambulatory medical care by women: United States, 1997-98," Vital and Health Statistics. Series 13, no. 149, pp. 1-46, 2001.

[49] I. Janssen, L. H. Powell, K. A. Matthews et al., "Depressive symptoms are related to progression of coronary calcium in midlife women: the Study of Women's Health Across the Nation (SWAN) heart study," American Heart Journal, vol. 161, no. 6, pp. 1186.e1-1191.e1, 2011.

[50] T. Rutledge, V. Vaccarino, B. D. Johnson et al., "Depression and cardiovascular health care costs among women with suspected myocardial ischemia. Prospective results from the WISE (Women's ischemia syndrome evaluation) study," Journal of the American College of Cardiology, vol. 53, no. 2, pp. 176-183, 2009. 


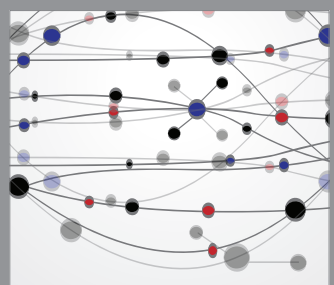

The Scientific World Journal
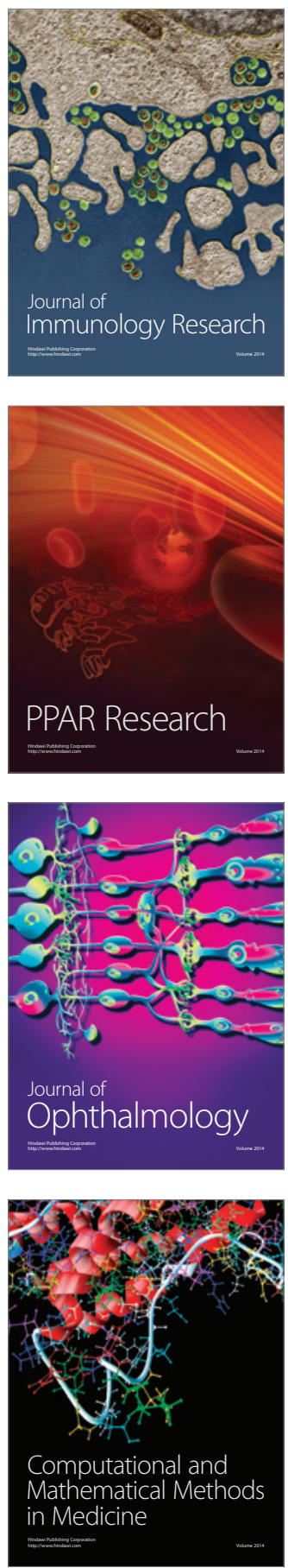

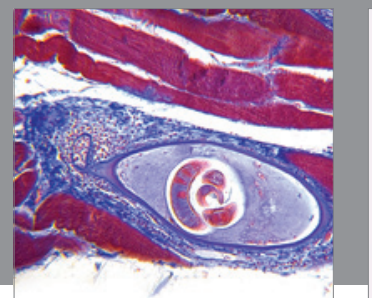

Gastroenterology

Research and Practice
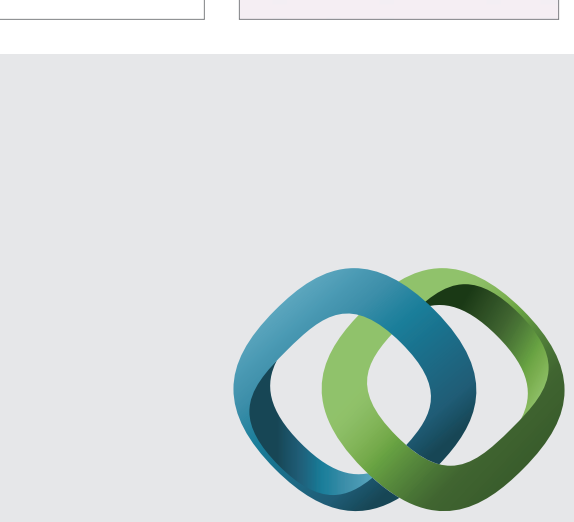

\section{Hindawi}

Submit your manuscripts at

http://www.hindawi.com
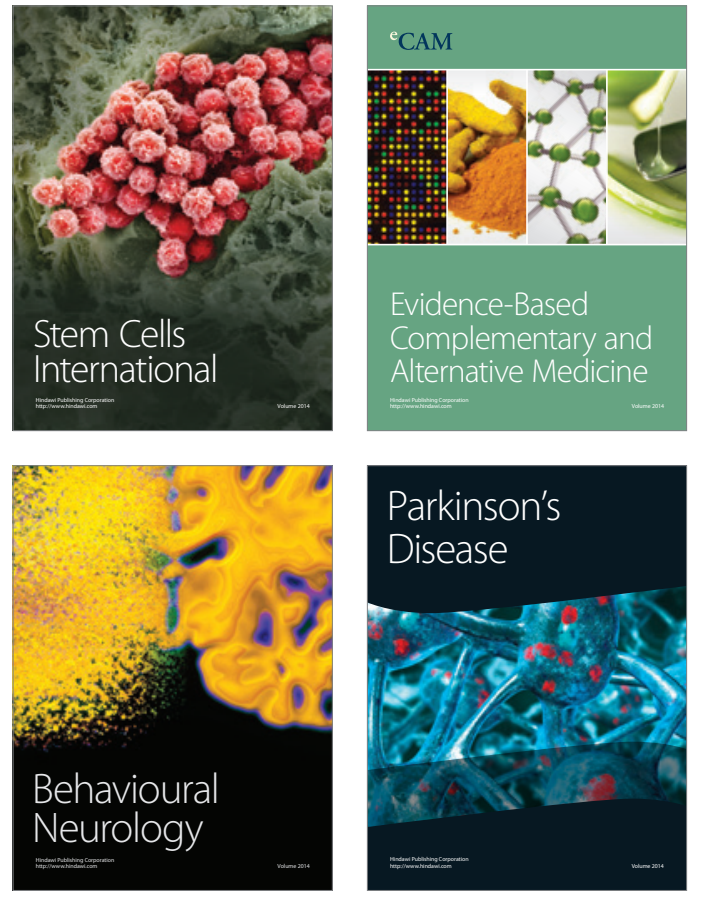
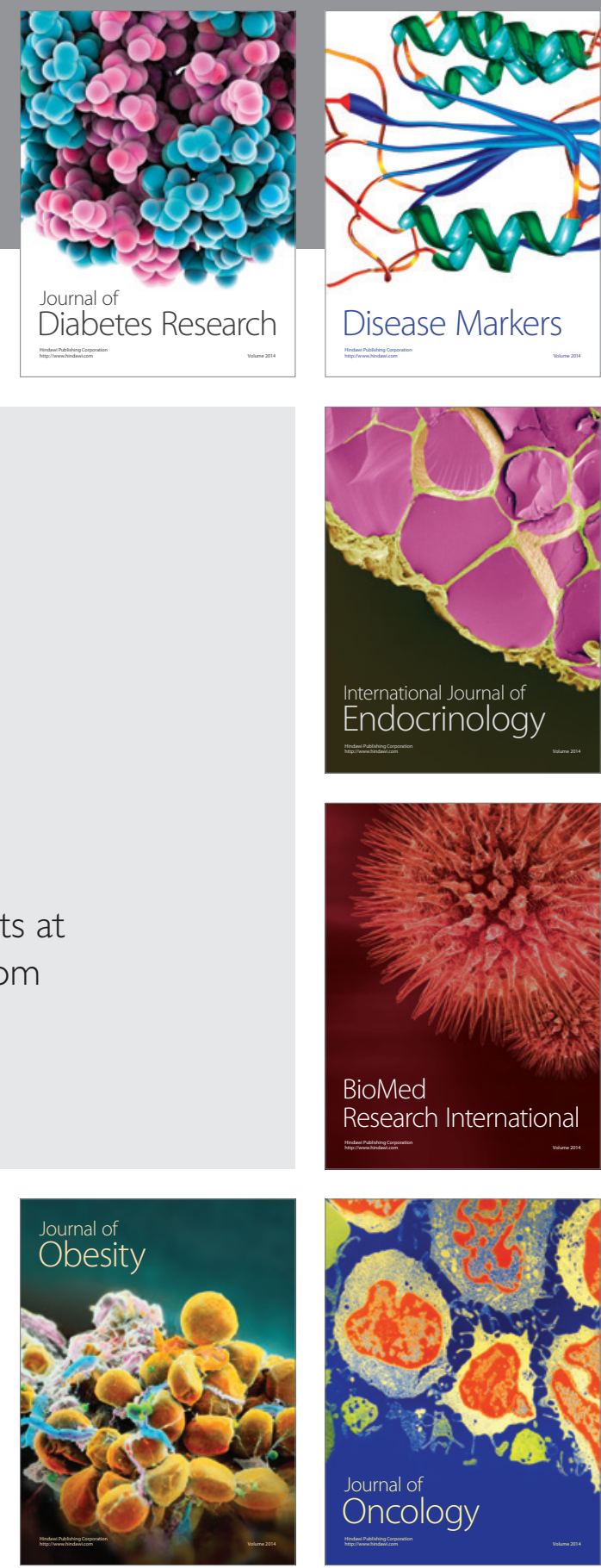

Disease Markers
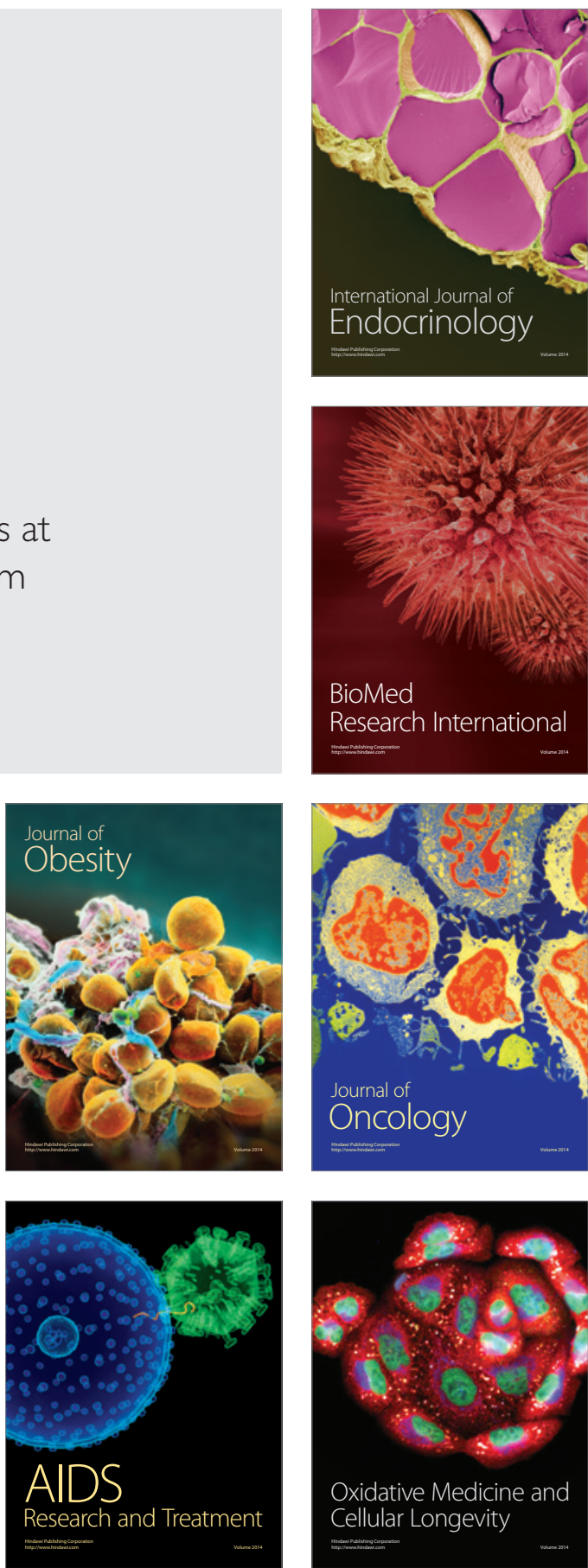